NIST Technical Note 1780

\title{
Towards Smart Fire Panels
}

\author{
Paul A. Reneke
}

http://dx.doi.org/10.6028/NIST.TN.1780

National Institute of Standards and Technology U.S. Department of Commerce 
NIST Technical Note 1780

\section{Towards Smart Fire Panels}

Paul A. Reneke

Fire Research Division

Engineering Laboratory

http://dx.doi.org/10.6028/NIST.TN.1780

February 2013

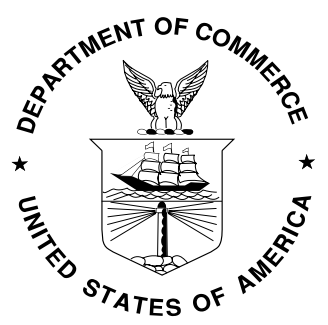

U.S. Department of Commerce Rebecca Blank, Acting Secretary

National Institute of Standards and Technology Patrick D. Gallagher, Under Secretary of Commerce for Standards and Technology and Director 
Certain commercial entities, equipment, or materials may be identified in this document in order to describe an experimental procedure or concept adequately. Such identification is not intended to imply recommendation or endorsement by the National Institute of Standards and Technology, nor is it intended to imply that the entities, materials, or equipment are necessarily the best available for the purpose.

National Institute of Standards and Technology Technical Note 1780 Natl. Inst. Stand. Technol. Tech. Note 1780, 33 pages (February 2013) http://dx.doi.org/10.6028/NIST.TN.1780 


\section{Table of Contents}

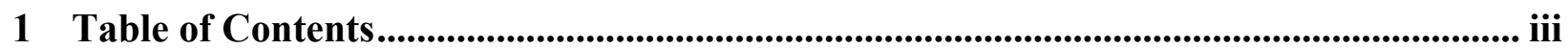

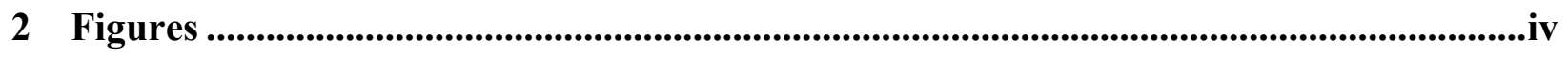

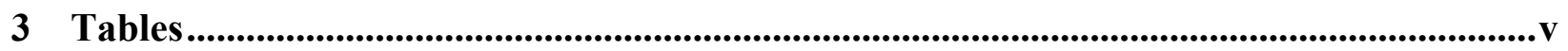

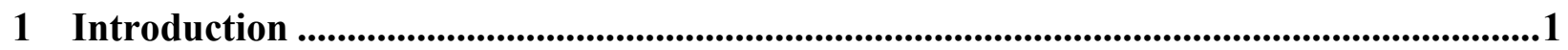

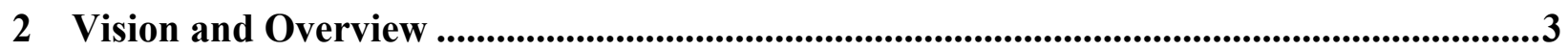

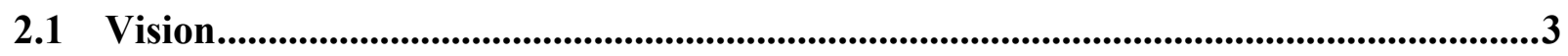

2.2 Review of Important Publications on Smart Fire Panels...................................................5

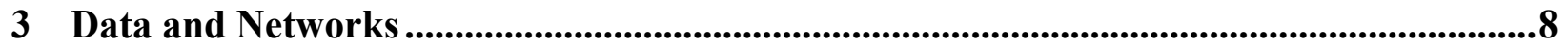

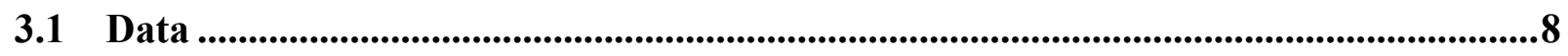

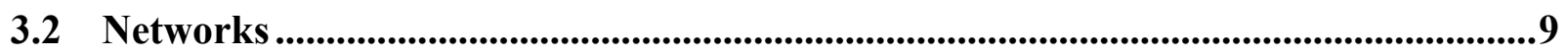

4 Decision Support Software: Making the Panel Smart .........................................................13

4.1 Evaluating Conditions ......................................................................................................13

4.2 Presenting information to first responders .....................................................................16

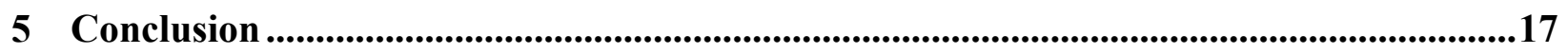

6 Acknowledgements .............................................................................................................18

7 Appendix A. Definition of Acronyms.......................................................................................20

8 Appendix B. Smart Fire Panel project paper by section .......................................................22

9 References ..........................................................................................................................................24 


\section{Figures}

Figure 1 Stakeholders in a building information system and smart fire panels. (Acronyms defined

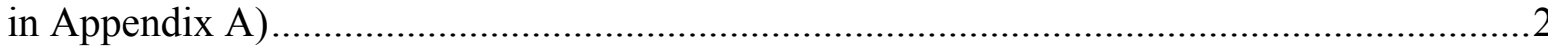

Figure 2 Pre-emergency plans, stored in notebooks, carried in the cab of an engine. Wilson, NC Fire/Rescue Services as shown in reference [4] ......................................................

Figure 3 En Route Screen from reference [10] .............................................................. 7

Figure 4 The alert location screen of NIST's BISACS showing the floor plan where the sensor resides as shown in reference [17]

Figure 5 Proposed Next Generation Network Communications for First Responders (CCCT

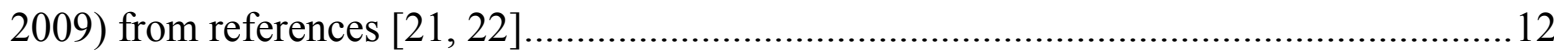

Figure 6 Thermocouple readings and SDFM prediction (from Toledo $\mathrm{OH}$ ) from reference [41] 15 


\section{Tables}

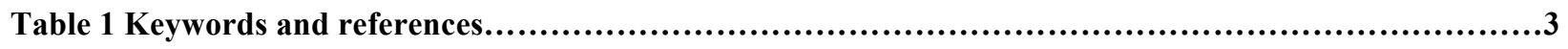




\title{
Towards Smart Fire Panels
}

\author{
Paul A. Reneke \\ Fire Research Division \\ Engineering Laboratory
}

\section{Introduction}

This note is a review of the last 13 years of work that has been done at the former Building and Fire Research Laboratory (BFRL), now the Engineering Laboratory (EL), at the National Institute of Standards and Technology (NIST) to provide reliable and useful information and tools to firefighters and other first responders when they are called to a large structure incident. Interest in making use of the increasing amounts of information that buildings collect with various sensors dates back to at least 1984 when NIST staff member Harold E. "Bud" Nelson suggested that there was a wealth of information being collected by buildings to control HVAC and other building systems that could be useful to the fire service [1].

The driving reason behind this interest has been the magnitude of the problem. Fire emergencies annually cause \$9.6 B in property losses to 524000 structural fires [2] and over 100 firefighters are killed and 80000 injured, yielding a net social cost of between $\$ 3 \mathrm{~B}$ and $\$ 16 \mathrm{~B}$ per year [3]. The magnitude of the potential impact makes the investment of time and resources needed to study the problem a worthwhile investment. Furthermore, as the Internet and building networks become more ubiquitous, as building systems become more intelligent, as wireless and cellular communications cover more area and as computers become more powerful and more portable, the environment becomes more favorable for the smart fire panel to succeed.

However, the task of actually creating a system of standards and protocols to allow first responders to communicate with alarm systems is daunting. There are many problems that cross many disciplines. Technical issues range from defining communications and network protocols, to creating and maintaining building information models, to understanding and interpreting the information, to presenting first responders with the information in a timely way, for example, the location of alarms in a building upon arrival.

An additional difficulty in moving forward is the number of stakeholders involved. Figure 1 shows graphically the range of stakeholders. No single organization exists to represent the many different stakeholders. 


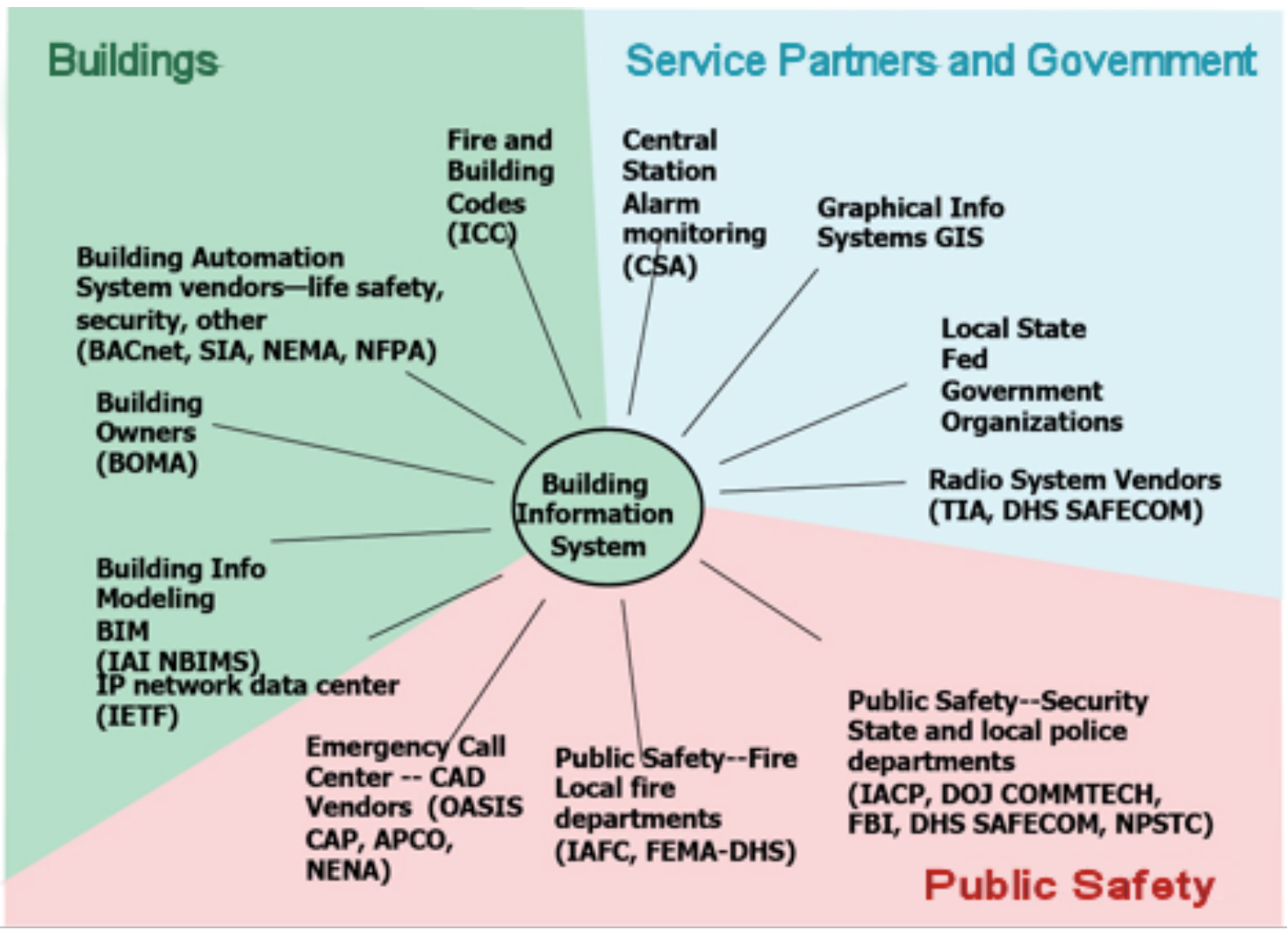

Figure 1 Stakeholders in a building information system and smart fire panels. (Acronyms defined in Appendix A)

To bring stakeholders together is as big a task as solving the technical issues involved.

NIST became interested in smart panel development because of its potential impact on life safety. This has connections with many of the stakeholders involved. In parentheses on Figure 1 are organizations that NIST works with on technical issues. NIST has substantial experience with the technologies involved such as network protocols, fire modeling, and sensor signals and has worked toward defining standards for smart fire panels using that experience.

In the following sections, the work to develop smart panels will be reviewed. Section 2 gives the vision for the smart fire panel effort and describes a number of publications that NIST has produced over the years to give an overview of the project at different points in time. As discussed previously, developing a smart fire panel crosses a number of disciplines. The effort can be broken into two major parts. The first part is discussed in Section 3. This includes both the network systems that gather information from the building and deliver it only to those authorized to have it; as well as the formats the information takes so that both sender and receiver are speaking the same language. The second part, discussed in Section 4, reviews the effort to take the information provided, interpret it and present it to first responders in a form they can quickly understand and use. Section 5 presents conclusion and recommendations for future research. 
In Appendix B the smart fire panel papers discussed here are listed by title, author and reference number for easy reference. Table 2 has a list of important keywords with related references.

Table 2 Keywords and references

\begin{tabular}{|l|l|}
\hline \multicolumn{1}{|c|}{ Keyword } & \multicolumn{1}{|c|}{ Reference number } \\
\hline Data Needs & 4,20 \\
\hline Decision support software & $10,49,51,52$ \\
\hline Early concept & $5,6,7$ \\
\hline First responder needs & $4,20,51,52$ \\
\hline Inverse modeling & $35,36,43,44$ \\
\hline Network protocols & $21,22,23,24,25,26,27$ \\
\hline Program overview & $8,9,10$ \\
\hline Signal analysis & $30,31,32$ \\
\hline Smoldering fires & 45,47 \\
\hline Virtual testing & 49 \\
\hline Workshops & $20,51,52$ \\
\hline
\end{tabular}

\section{Vision and Overview}

\subsection{Vision}

Davis and Evans provided a clear vision of what NIST has been working for in the 2004 Fire, Suppression and Detection Symposium [4].

Response to a building emergency typically commences with notification from a central alarm or security system monitoring service or 911 center. The first responder is provided with the type and location of the incident. A map of the running routes and hydrant locations is used by the responding apparatus. The extent of the building information on the route map depends on the type and use of the building. For commercial buildings or apartment houses, the route map may include an outline of the building and the location of the standpipe/sprinkler connection and door/garage entrances. For newer buildings, the location of the fire alarm annunciator panel 
and fire control room is sometimes available. "First due" firefighters responding to the alarm prepare mentally for the typical fire expected in the class of structure identified.

Additional information about the structure may be available in binders or file boxes carried in the responding apparatus. An example is shown in [Figure 2]. These pre-emergency surveys may contain interior floor plans, stairwell risers, the location of utility shutoffs, known hazards, etc. Its detail will depend on the person who conducted the survey.

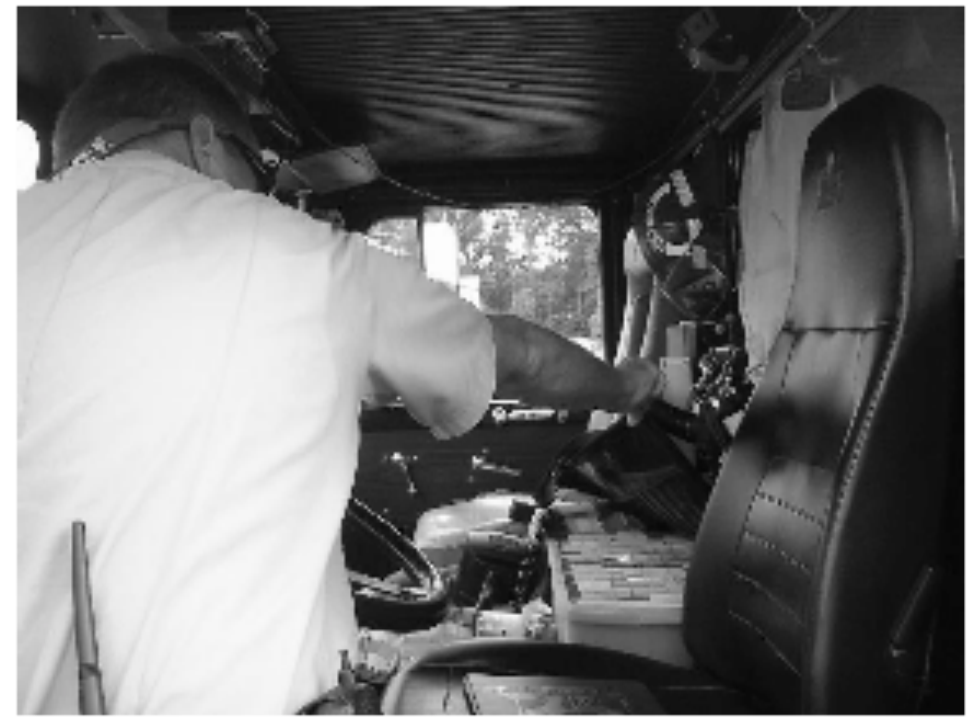

Figure 2 Pre-emergency plans, stored in notebooks, carried in the cab of an engine. Wilson, NC Fire/Rescue Services as shown in reference [4].

With the development of small, rugged, portable computers and compact electronic storage media, fire departments are moving toward using electronic pre-emergency surveys (e-plans) for buildings that can be accessed from mobile computer terminals in the apparatus. Advances in telecommunications have opened up the possibility of supplying first responders with access to municipal databases and real-time information from sensors and alarm systems in buildings prior to arrival. The potential amount of information that can be available to first responders is staggering.

In the future, first responders will make use of data from many sources in responding to emergencies. For enhanced reliability, critical information for use in the initial emergency response will be carried with the responders. Other information may be transmitted. The transmitted information may come from both secure and public municipal databases and also from inside building systems. Using the pre-emergency survey diagrams as a platform, incident commanders may have displays of relevant building and surrounding area information from the databases (static data) and real-time building sensor and alarm information (dynamic data) to 
use as decision aids. Electronically transmitted information about conditions in the building can be used as input to predictive models that can forecast the development of hazards. Output from predictive models can improve the situational awareness of the incident commander to the development of potential hazards well beyond the capabilities that exist today.

The following sections will review the progress NIST has made and recommendations for the future.

\subsection{Review of Important Publications on Smart Fire Panels}

There have been a number of both technical and more general papers published to communicate NIST's effort and the potential for the smart fire panel.

In 1998 and 2001, NIST researchers made the case that fire science and the current state of technology were both reaching a level sufficient to start the development of smart fire panels [5, $6,7]$. These papers focused primarily on the emerging technologies that would make such panels possible as well as the benefits to the first responder community. Each of these is described below.

"Using Sensor Data to Predict the Environment in a Building" Jones et al 1998, [5] is a discussion and demonstration of the possibility of combining building sensor data with a fire model to predict the intensity of a fire in a building. As an example, the zone fire model CFAST [28] is used to make a prediction of conditions in a room fire experiment and then uses data from the early part of the experiment to improve predictions for that rest of the test. One of the significant deficits in knowledge identified is a need for better mathematical models of how sensors react to environmental changes, including but not limited to fires.

In 2001, Jones and Bukowski presented "Using High Reliability Detection for Fire Service Response in Buildings" [6] at the International Conference on Automatic Fire Detection (AUBE01). This paper provides an early and high level description of what a smart fire panel system would do and the different technologies that would have to be developed to support it. Three research threads are identified:

1. A computational model of the fire environment fast enough to make real-time predictions,

2. A better understanding of how sensors are used in buildings, and

3. A measure of the quality of a computer model prediction to actual data as a means of establishing confidence in the prediction.

"Critical Information for First Responders, Whenever and Wherever It Is Needed," written by Jones and Bukowski 2001 [7], was another high level discussion of the purposes and needs for a smart fire panel, the technologies available to make it happen, and the theoretical understanding needed to provide a measure of certainty in the information being provided to the fire service. The authors argue for using available technology as much as possible, but also for the 
development of new technologies where needed, to provide early warning of system malfunction, identification of hazardous environments, in-situ monitoring and prediction for building managers and real-time assessment of firefighter conditions. While the long range goal is to be able to "provide building information wherever and whenever needed," the identified first application is to provide first responders with information about fire size, location and rate of growth.

By 2006, technical work was focused on building data modeling, communications and decision support software. Holmberg et al wrote "Building Tactical Information System for Public Safety Officials. Intelligent Building Response (IBR)" [8]. It is a technical summary of the project by the same name sponsored by National Institute of Justice (NIJ). As Holmberg states:

The main goals of the project were to: (i) gather information about what information first responders need; (ii) develop a standard path for moving data from buildings to first responders; (iii) demonstrate the proposed technology with a video to document the demonstration; and (iv) address security concerns of the information transfer.

As part of the effort to disseminate the information to the general fire community Holmberg and Davis each wrote an article for different trade journals. One article was aimed at the firefighter community and the other at fire protection engineers.

Holmberg's "Smart Talk" for Fire Chief [9] explained the concept of smart buildings providing information to first responders and fire panels. He describes how smart buildings could help firefighters in their effort to more effectively and safely address emergency situations. The article focuses primarily on the real-time data that a building can provide to first responders and the networking side of the problem though it does mention decision support systems.

In Fire Protection Engineering, Davis 2007 wrote "Intelligent Building Responses" [10] to inform the engineering community how the new smart panel technology could impact emergency response. The article focused primarily on the delivery of information to first responders. As Davis writes, "Building information displayed to emergency responders must be easily understandable and supply the needed information quickly while avoiding information overload." In pursuit of that goal Davis briefly discusses the efforts of NIST and the National Electrical Manufactures Association (NEMA), including NEMA's Fire Service Annunciator and Interface Standard Reference Standard (SB30). He includes examples of a test platform that NIST developed, one of which is shown in Figure 3. 


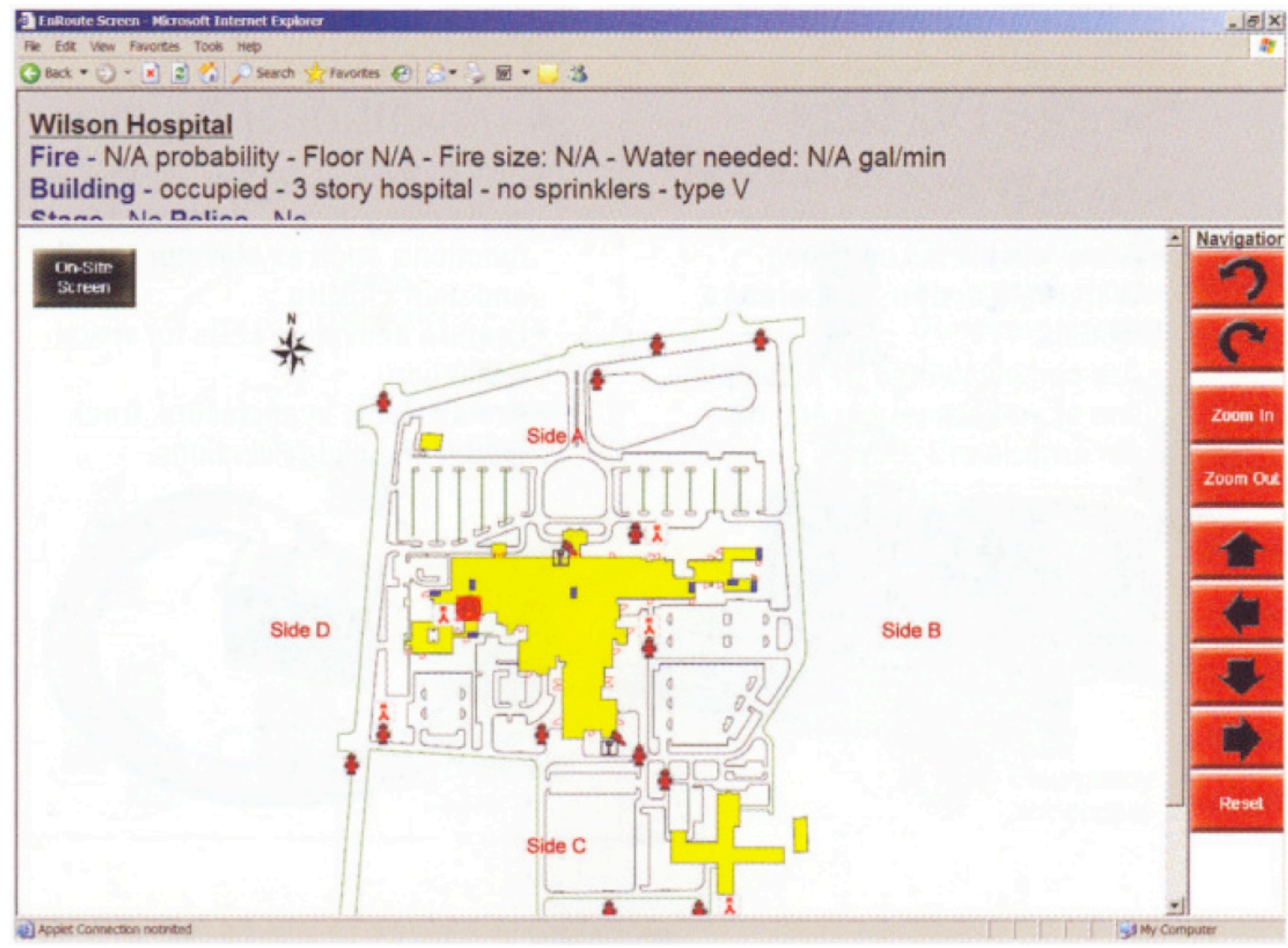

Figure 3 En Route Screen from reference [10]

The En Route Screen is meant for use while traveling to the incident, in this case a fire. The information is displayed within a browser window. At the top, information is shown about the building with a schematic of the footprint of the building including approach roads, and locations of hydrants. Within the footprint of the building, the grey boxes give approximate locations of stairs. The red box is the approximate location of the alarm that has been activated. Once onsite a second screen with more detailed information about the internal layout of the building can be shown. 


\section{Data and Networks}

NIST has a long history in working with building networks and building information models. NIST was one of the voting organizations on Standards Project Committee (SPC) 135P at the American Society of Heating, Refrigerating and Air-Conditioning Engineers (ASHRAE). This committee developed the Building Automation and Control Networks (BACnet) protocol, first published in 1995 and today widely used international standard $\left[11,12,13,{ }^{14}\right]$. One feature of BACnet is that it has enabled the integration of fire alarm systems with other building automation and control systems $[15,16]$. This previous experience provided insight for development of network protocols needed to transfer information quickly and securely.

The National Bureau of Standards (now NIST) has been working in the field since its development of SASE (Standards, Analysis, Synthesis and Expression) software [17]. This work continued into the development of ISO 10303-Product Data Representation and Exchange [18] also known as the Standard for Exchange of Product Model Data or STEP. A more detailed history of building data standards is available from Fenves et. al. [19].

\subsection{Data}

Initially, work in this area focused on identifying the kind of data that would be of most use to first responders. While much data may be available, it is important to limit the information delivered to useful data without overloading the first responders.

The Davis and Evans article 2004 [4] (partially funded by the National Institute of Justice (NIJ)), focuses on what information is available, what fire-related information is useful and when it is useful. A fire response can be broken into three periods: (1) the time from dispatch until the "first due" arrives, (2) the time from arrival until the size of the incident and tactics have been determined referred to as "sizing up" the incident and (3) the mitigation period. Each time period has a set of tasks and includes extensive lists of needed information that is useful for each time period. For each time period, the information can be further characterized as static, dynamic and calculated decision support. Static information includes most of the information that fire departments pre-plans such as building occupancy and location of hydrants. Dynamic information includes alarms that have been activated and the current conditions of building systems such as the HVAC system. Decision support calculations include the level of confidence that the alarm is or is not a false alarm and probable size and location of the fire.

In "Workshop to Define Information Needed by Emergency Responders During Building Emergencies," Jones et al 2005 [20] document a workshop organized as part of a Department of Justice, Office of Community Oriented Policing Services (COPS) project entitled "Building Tactical Information System for Public Safety Officials." It brought together representatives from police, fire, medical, building technology, government and security communities to discuss 
the information needs of first responders. The workshop results included (1) identification of building information needed by first responders prior to reaching the scene and once on scene, (2) understanding the importance of using both audio and visual methods to present information in as simple a form as possible, (3) recognition that the limited time an incident commander has enroute to an incident means the amount of information presented must be limited, (4) audio information can be useful to those responders unable to view the visual information, and (5) information needs for police and EMS were included along with the recommendation that more discussion with more representatives of these communities would be needed.

Both Davis and Evans [4] and Jones et al [20] divided information into two categories, static and dynamic, and identified similar though not identical data that is needed and available. Both also noted the importance of understanding the limited time first responders have between initial notification and arrival on scene and the importance of limiting the information being presented to data of immediate importance. Finally, Davis and Evans and Jones et al. found that there is significant potential for decision support software to improve first responder operations.

\subsection{Networks}

Once the effort to define the information needed was established, the focus turned toward the communication of the information from a building through a smart panel to the first responders. NIST focused its effort to develop the Building Information Services and Control System (BISACS) protocol. A number of papers were written that specified and demonstrated BISACS as discussed below.

In "Building Information for Emergency Responders," Treado et al. [21] describe a methodology for controlling access to building information to approved external entities such as police, fire and public safety. The methodology includes BISACS and standardized data modeling using an extension of the BACnet protocol called the Building Automation System (BAS). BAS is designed to sit between BISACS, which communicates with the world and BACnet, which communicates with the building systems. The BAS system has two interfaces. The first is the Building Services Interface to allow outside computer systems like BISACS to connect and secondly the Credential Reader Interface that allows individuals with appropriate Personal Identity Verification (PIV) card access.

The report, "Building Information Services and Control System (BISACS): Technical Documentation, Revision 1.0" [22] is the technical description of BISACS. The stated goal of BISACS "is to create a computer based system that allows external users to be verified and then logged into the system in order to gain access to building information such as its structural layout and/or to monitor a particular building or set of buildings for alerts."

Two types of servers, the BISACS Base Server (BBS) and the BISACS Proxy Server (BPS) are described. The BBS serves as the lowest level nodes in the BISACS network and connects to Service Interfaces (SI) and various monitored devices on the network. The BPS actively 
monitors BBSs and other BPSs. The system provides a user verification process and makes use of CAP. The system is designed to scale for a single building or small group of buildings to a nationwide system.

As part of the documentation, a small number of example screens that represent a web based implementation are shown. An example of the information that can be transmitted and displayed using BISACS is shown in Figure 4.

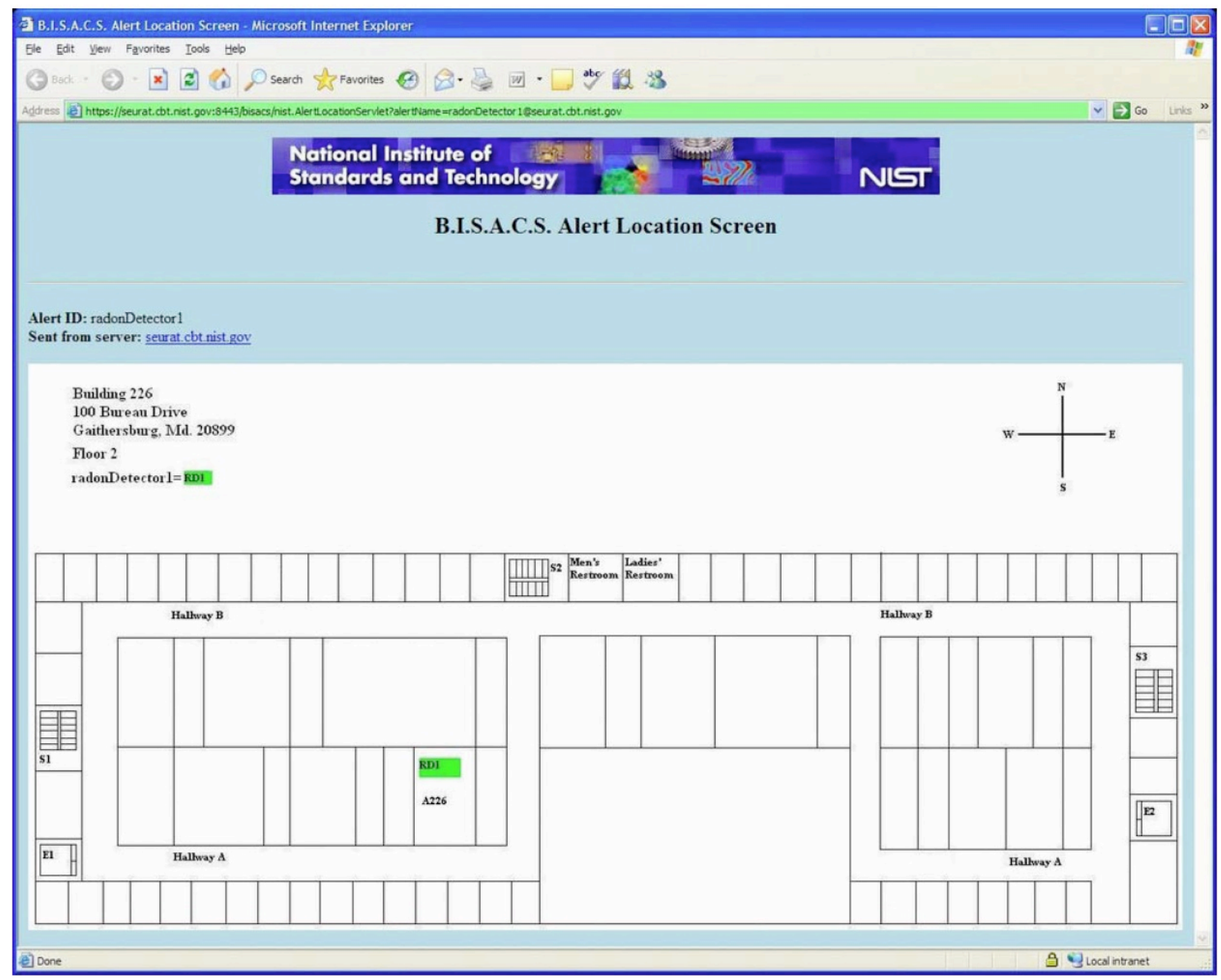

Figure 4 The alert location screen of NIST's BISACS showing the floor plan where the sensor resides as shown in reference [22]

The BISACS is designed to collect, secure, encrypt, transmit and display building data and is intended to test various aspects of a network system that could be used by first responders.

In 2008, Vinh presented "Computer-based Monitoring for Decision Support Systems and Disaster Preparedness in Buildings" [23,24]. Vinh described the BISACS and its two main components, BBS and the BPS. The results of a demonstration project where solutions to a number of issues, including security, communications, data handling and interface standards is 
presented. Future research such as working with existing standards, like the BACnet Web Services standard (BWS) and the NEMA SB30 are also discussed.

A workshop on information exchange was held in October 2008. It is documented in "Building Information Exchange for First Responders Workshop: Proceedings" Averill et al 2011 [25]. The workshop brought together first responders, government officials, practicing engineers and researchers to discuss making building information available to first responders in an emergency. The primary purpose of the workshop was to initiate possible collaboration opportunities. The Public Safety Answering Point (PSAP) along with BISAC, Common Alerting Protocol (CAP) and other protocols were a central part of the discussion. After two days of wide-ranging discussions, a large number of technical issues were identified that still needed to be resolved. Some of the issues still to be resolved include:

- Ownership and maintenance of databases,

- Choice of standard communication protocol,

- Establishment of criteria to route calls based on the content of the message,

- Implementation of appropriate authorization and security systems, and

- Development of multihazard scenarios for system design and compliance.

In "Connecting Buildings to Public Safety Networks," Vinh and Holmberg 2009 [26,27] present a framework built to use standards-based communications over public safety networks. The complexity of the issues involved in connecting a number of different networks using different protocols is apparent from Figure 5. 
NG9-1-1, CSAN, PSAP and BISACS Integration

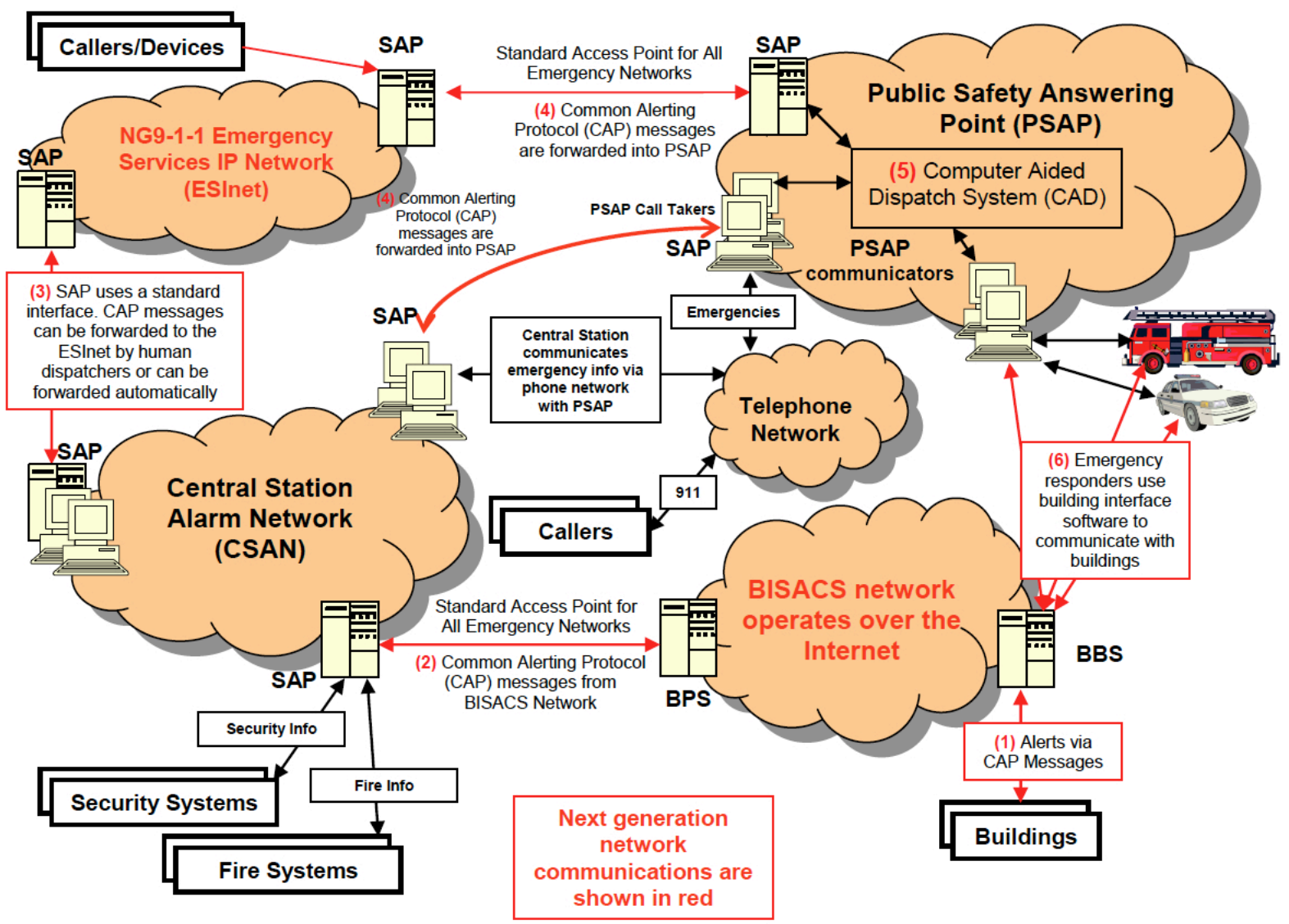

Figure 5 Proposed Next Generation Network Communications for First Responders (CCCT 2009) from references [26, 27]

"The framework for monitoring and sending building alerts to the first responder community was proposed via the Building Information Services and Control System (BISACS); the Common Alerting Protocol (CAP) was proposed as the standard for encapsulating the alerts and their contents; a standard way to classify and to categorize the alerts so that filtering can be done on alert contents was proposed; the Standard Access Point (SAP) was proposed as the standard mechanism for communicating the alerts between the various public safety networks; the Application Specific Client (ASC) was proposed as the standard way to connect back to the building to assess the emergency scenarios." Schematics showing building layout and location of sensors that have alarmed were also discussed. 


\section{Decision Support Software: Making the Panel Smart}

Decision support software has two parts. Part one is evaluating the situation and part two is communicating that knowledge to the user in a way that is consistent with anticipated choices. An important part of evaluating a fire emergency is being able to predict or model the effects of fire. NIST is a leader in computer fire models including the zone fire model CFAST [28] and the computational fluid dynamics model FDS [29]. This knowledge serves as the foundation for developing tools such as the Sensor-Driven Fire Model (SDFM) discussed in the next section.

In Section 4.2, supplying first responders with usable information is discussed. It is necessary to develop software that is practical and user-friendly. This requires several steps, including definition of needed information and the development of formats that would most easily communicate that information. The software also must be tested to ensure its effectiveness.

\subsection{Evaluating Conditions}

The translation of sensor data into usable descriptions of building conditions is a central task required to inform first responders. There are three tasks to this problem. The first is to be able to extract underlying trends and values from the inherently noisy instantaneous measurements of building sensors. The second task is to take the sensor data, such as temperatures, and estimate the fire size and growth curve, called the heat release rate (HRR), that would produce that sensor reading. Finally the estimated fire HRR curve from task two is projected forward to estimate the conditions at some point in the future. The final task is well understood because this is what fire models such as CFAST do. The first two tasks were the main focus of research in this program.

"New Approaches to the Interpretation of Signals from Fire Sensors" Bukowski and Reneke 1999 [30,31,32] is an early discussion of the ability to use sensor data and computer fire models to make more accurate detection of fires and to provide current and developing conditions to fire service. Bukowski and Reneke demonstrate a simple algorithm for updating a previous estimate of the HRR curve of a fire by comparing the resulting upper layer temperature to the measured temperature. One of the challenges is to determine when the estimate of the HRR curve is good enough. For this task they make use of the idea of functional data analysis to develop the difference between the estimate and the actual measurements. For more information about functional data analysis, see reference Ramsay and Silverman [33] for a general treatment and Peacock et al [34] for applications to fire science.

In their paper "A Sensor-Driven Fire Model, Version 1.1," Davis and Forney 2001 [35] document the Sensor-Driven Fire Model (SDFM). They also presented an overview of the SDFM at AUBE01 [36]. SDFM is an inverse fire model. An inverse model takes equations that describe how a particular input gives a resulting condition, for example an equation that relates the HRR of a fire to the temperature of the upper layer, and inverts it. In this case the equation 
would be inverted so that given a particular upper layer temperature we would get the HRR of the fire. The SDFM is designed to take the output history of fire detectors and estimate the HRR time history of the fire and then, making estimates for the growth rate of the fire in the future, estimate the amount of time until conditions become hazardous in a compartment.

The model was verified against two fire tests. One was a three room single-level experiment using a methane burner and the other was a seven room two-level structure using wood pallets as the fire source. In each case data from a single thermocouple in each zone is provided to the SDFM and the model estimates compartment conditions and fire size. The SDFM compared reasonably well with the experiments. It was also found that the SDFM could produce a scenario much faster than real-time even for computers of the year, 2001.

The SDFM is an example of how the NIST's previous work was beneficial to the smart panel work. SDFM arose out of a zone fire model called JET $[37,38]$ that was developed specifically to test a new plume and ceiling jet algorithm [39] developed because of experiments on large fires in aircraft hangers [40,41]. As part of the smart panel project, both JET [42] and the SDFM [43] were updated in 2010.

"Using Sensor Signals to Analyze Fires" Davis et al. 2002 [44] discusses the development and verification of an algorithm that can take data from smoke and gas sensors in the ceiling jet of a fire and predict the heat release rate of the fire. While the ceiling jet created by a fire plume is, as the name implies, at the ceiling and so not a direct threat to any occupants, it is of fundamental importance in predicting sensors that are on the ceiling and thus in the ceiling jet. The algorithm was included in the SDFM. The algorithm gave very accurate predictions for $\mathrm{CO}$ in the ceiling jet with accurate information about the amount CO in the upper layer. Smoke measurements had a discrepancy that limited the ability of the algorithm to estimate the smoke level.

"Discriminating Between Smoldering and Flaming Fires Using Alarm Signals" Davis 2010 [45] addresses how to tell the difference between a smoldering and small flaming fire. While the SDFM is able to use sensor data to predict the position and growth of a flaming fire it wasn't designed to predict or even to identify smoldering fires. A number of small flaming and smoldering fire tests as well as nuisance tests are reported on. The tests included collecting data from thermocouples and photoelectric smoke alarms from multiple positions in a normal sized room. The results are used to develop a methodology that decision support software could use to discriminate between smoldering and flaming fires.

The methodology looks at information from two sensors. As long as the smoke detector measures a smoke extinction level less than $0.01 \mathrm{~m}^{-1}$ everything is fine. When the smoke extinction level exceeds $0.01 \mathrm{~m}^{-1}$ then measurements from a heat detector are taken. If the excess temperature exceeds $4{ }^{\circ} \mathrm{C}$ and the rate of change is $>0.01{ }^{\circ} \mathrm{C} / \mathrm{s}$ the source is a flaming fire and $\mathrm{SDFM}$ can be used. If either condition is not met the source is a smoldering fire. More work is needed to check how generalizable the results from this specific set of tests are. 
"Alarm Information for Decision Support" Davis et al 2010 [46] uses a set of experiments performed in a former school building in Toledo, $\mathrm{OH}$ to examine two approaches to using heat detector data to provide decision support to an incident command. The first method used the data directly, associating a particular temperature with a particular level of risk. The second, processed the temperature data through the SDFM to estimate other environmental conditions. As part of the analysis, predictions of the SDFM are compared to measured conditions as shown in Figure 6.

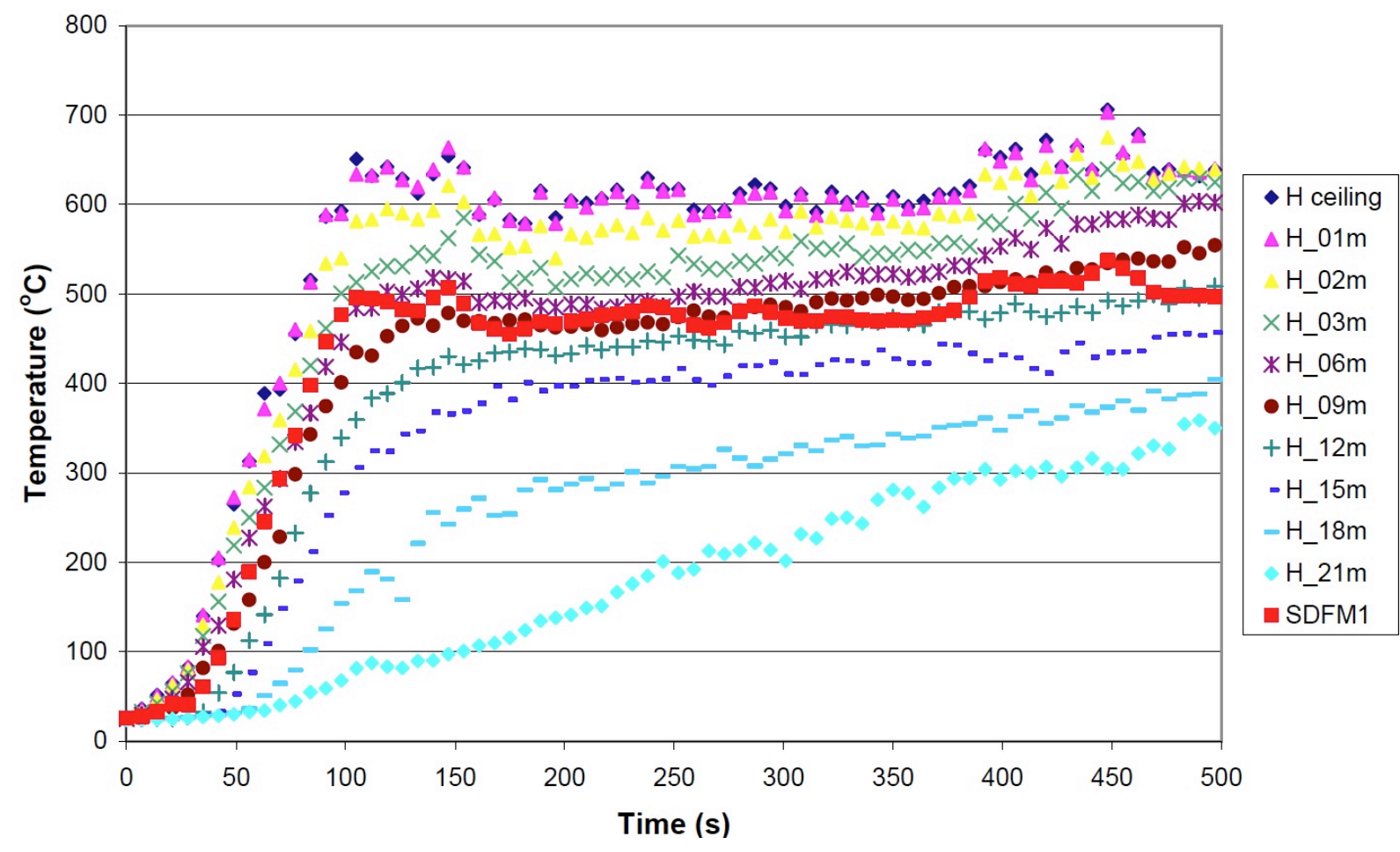

Figure 6 Thermocouple readings and SDFM prediction (from Toledo OH) from reference [46]

Davis et al report that both methods provide an assessment of the thermal conditions but more testing is needed before the either method can be implemented in decision support software.

Smoldering fires can be a difficult challenge for the current generation of fire detection systems. Smoldering fires are important for two reasons. First, smoldering fires can create a toxic environment that can harm occupants. Secondly smoldering fires can transition to flame fires, for example, a smoldering cigarette on a sofa. With these two concerns in mind, improving detection of smoldering fires with a smart fire panel has the potential for significant improvements in life safety and property lose.

One method of tracking smoke from a smoldering fire through a building was investigated in "Modeling Smoldering Fires Using the Computer Model CONTAM" Davis 2010 [47]. CONTAM [48] is a multizone indoor air quality and ventilation analysis computer program. This investigation explored the use of CONTAM to calculate smoke flows in a building from a 
smoldering fire. While CONTAM could be used to calculate smoke flow, the calculated values have some significant differences from experimental measures. There is still work to do before CONTAM could be used to track smoke. The most significant issue identified is the need to model the rise in temperature a compartment may experience with a smoldering fire. The reason is that differences in temperature between two rooms connected by an opening, for example a door, will drive the airflows between the rooms. If a smoldering fire increases the temperature of a room the smoke will flow more quickly into other rooms.

\subsection{Presenting information to first responders}

An important part of any decision support software is its ability to supply useful information in a timely fashion. "Studying the Response of Building Systems to Fire Using a Virtual Cybernetic Building Test-Bed" Davis 2003 [49] presents an overview of a part of the effort to develop decision support software, using the Virtual Cybernetic Building Test-Bed (VCBT) [50]. The NIST VCBT is designed to link real building components such as HVAC controllers to computer simulations of normal operation or emergency incidents such as fire. The VCBT works by linking together different models such as CFAST, a zone fire model, and a model of an HVAC system, to predict the evolving conditions in a building.

In the report entitled "Workshop on the Evaluation of a Tactical Decision Aid Display" Davis et al 2005 [51] document a workshop for fire service and fire safety personnel with two goals. The first they presented a history of NIST's efforts in developing smart tactical displays as well as the status of "Building Tactical Information System for Public Safety Officials." The second goal was a hands-on exercise to give participants a chance to interact with prototypes and evaluate their strengths and weaknesses. Comments were grouped into four major categories: the interface, standards, concerns, and other issues. They ranged from the specific, such as making buttons larger because firefighters will be wearing gloves, to the general, such as concerns about information overload and network security. The comments were used to improve the interface for field demonstration, which is described next.

In "Demonstration of Real-Time Tactical Decision Aid Displays" Davis et al 2007 [52] presented results of a field demonstration of two prototype tactical decision aid computer interfaces in Wilson NC. Honeywell Inc. and NIST worked with the City of Wilson Fire Department and Wilson Memorial Hospital to demonstrate the real-time wireless transmission and display of simulated building data to the Wilson Fire Department, a fire truck and the Honeywell Inc. ONYX FIRSTVISION fire panel. The demonstration was sponsored in part by the Department of Justice Community Oriented Policing Service (COPS) via the NIST Office of

Law Enforcement Standards (OLES). Descriptions of the scenario used, the issues that arose and feedback from the Wilson Fire Department are discussed in some detail. There was a generally positive response to the use of these tools.

The comments are broken up into four sections: general comments, standardization, display screens and information overload, and finally reliability of the system. The comments tend to 
focus on specific needs like larger buttons on the touch display to accommodate gloves or specific information that should be displayed including a clear indication of the first alarms as opposed to secondary alarms, to desires such as an indication of where occupants are in the building.

The standardization section focused on the need for panels to have some standardized functions to reduce the learning curve of new systems. One of the participants is quoted as saying, "My fear is that in order to create selling points for their systems to the client they start adding bells and whistles to make it appealing to the client but to us, the emergency responder, it is information overload and of no use to us, stuff we do not need."

In the Display Screen and Information Overload section of the report, there was a significant amount of concerned expressed about the usefulness of the information. The general consensus was that the "En Route" screen would be most useful to the first arriving apparatus, while the "On Site" screen would be of more use to the incident commander or apparatus called later in the fire. A flavor of the comments is represented by an officer who said that, "the command staff has time to look at it, but me going down the road in fire apparatus looking at a small computer screen; if the original alarm is flashing I can know to go to the rear instead of the front."

Other officers felt that, "The more you use a system like this, the more comfortable you will be." With time and training another officer could see the potential, saying "I can see a lot that this can be used for, the first-in apparatus, and incident commander. To be able to see the room of origin, where the problem is located. It may look overwhelming at first, but as you get used to it, it gets better."

The Reliability of the System section noted concerns with the accuracy of the information being presented. Not only the dynamic data but the static information. As noted by one participant, "Some of the information presented will depend on how accurate the premises keeps the information, how often will it be updated." One participant summed up the issues with sensor data and decision support calculations, "there is always a concern when you are trying to predict

off a sensor because a sensor is a spot detector, it tells you what is happening at that spot, but not in the room. An accuracy check or algorithm can be put in the system. Reliability of predictions is important."

NIST demonstrated the ability to transmit real-time building information to remote locations and fire apparatus.

\section{Conclusion}

For the last 13 years, NIST has had a sustained effort in working toward smart fire panels. Since Nelson's first suggestion, [1] NIST and many affiliated organizations have been working toward building support for the idea in early conceptual discussions at international technical 
conferences in the late 90s $[5,6,7]$ and keeping stakeholders apprised through standards committees and publications of developments in the area $[8,9,10]$.

NIST, in conjunction with others including the fire service, fire rescue and police, has developed a first draft of the information the fire departments needs in terms of data and networking [4,5]. It has also developed the technology to communicate this information including the BISACS [21-27], which can connect buildings to Public Safety Networks and allow for secure access to a building's systems by authorized external entities.

In terms of decision support, NIST has developed a number of tools to take data from smoke, heat and CO detectors and infer current and probable future conditions [30-44,45,46]. NIST also has worked with fire departments and others, especially the City of Wilson Fire Department, to develop methods to relay the information to personnel on scene so they can make informed decisions [51,52].

NEMA has passed the SB30 standard. Also the SB30 standard has been adopted for inclusion in NFPA 72.

Future research is needed to secure network communications and building data models. The fundamental roadblock to moving forward is a secure standard method of transmitting a standard set of data in a standardized format. Because of liability issues, security has to be addressed. Until a building owner can be sufficiently assured that unauthorized access to building information and controls will be prevented, the costs of considering these systems is likely to be seen as too high.

The second issue is to standardize the information presented to first responders, which means standard building data models. The discussion at several workshops [51, 52] shows that a big concern is the amount of training a first responder would need to make use of this technology. As described in Davis and Evans [4] and Jones et al [20] first responders have a limited amount of time. If systems vary significantly it is likely that first responders will just ignore the systems completely, meaning they will not provide extra value to the customers and so will likely again be seen as too costly.

These are the major problems that need to be addressed. However, progress has been made and as networks get faster and more prevalent, detectors become smaller and less expensive, and computers become more powerful, the potential for impact on public safety using smart panels continues to expand.

\section{Acknowledgements}

This work summarizes the work of a number of people. The author wishes to acknowledge the hard work and talent that went into this effort by Jason D. Averill, Adam Barrowy, Lori D. Brassell, Richard W. Bukowski, Steven T. Bushby, Thomas G. Cleary, William E. Davis, 
Michelle K. Donnelly, David D. Evans, Glenn P. Forney, Micheal Galler, S. Hellerman, David G. Holmberg, Walter W. Jones, J. Kostecki, Jessica Kratchman, Richard D. Peacock, Kent A. Reed, Stephen J. Treado, Robert L. Vettori, and Alan Vinh. 


\section{Appendix A. Definition of Acronyms}

APCO - Association of Public Safety Communications Officials

AUBE - International Conference on Automatic Fire Detection

BACnet - Building Automation and Control Network

BBS - BISACS Base Server

BCF - Border Control Function

BJA - Bureau of Justice Assistance

Bldg - Building

BPS - BISACS Proxy Server

BIM - Building Information Model/Modeling

BIS - Building Information System

BISACS - Building Information Services and Control System

BOMA - Building Owners and Managers Association

CAD - Computer Aided Dispatch

CAP - Common Alerting Protocol

CSAA - Central Station Alarm Association (a.k.a. CSA for short)

CSAN - Central Station Alarm Network

DHS - US Department of Homeland Security

DMIS - Disaster Management Interoperability Services

DOJ - US Department of Justice

DOJ COMMTECH - US Department of Justice, Communications Technology

ECC - Emergency Communications Center (associated with PSAP)

ECRF - Emergency Call Routing Function

EDXL - Emergency Data Exchange Language

ESINet - Emergency Services IP Network

ESRP - Emergency Services routing Protocols

FBI - Federal Bureau of Investigation

FCC - Federal Communications Commission

FED - Federal

FEMA - Federal Emergency Management Agency

GIS - Geographic Information System

GJXDM - Global Justice XML Data Model

HTTP - Hypertext Transfer Protocol

HVAC - Heating, Ventilation and Air Conditioning

IACP - International Association of Chiefs of Police

IAFC - International Association of Fire Chiefs

IAI - International Alliance for Interoperability

ICC - International Code Council

IETF - Internet Engineering Task Force

IEP - Information Exchange Packages

IJIS - Integrated Justice Information Sharing Institute (a.k.a. IJIS Institute)

IS - Global Information Sharing Initiative

IP - Internet Protocol

LG - Local Government

LIS - Local Information Server

LoST - Location to Service Translation

NBFAA - National Burglar and Fire Alarm Association

NBIMS - National Building Information Model/Modeling Standard

NEMA - National Electrical Manufacturers Association

NENA - National Emergency Number Association 
NFPA - National Fire Protection Association

NG9-1-1 - Next Generation 9-1-1 (a.k.a. NG for short)

NIEM - National Information Exchange Model

NIST - National Institute of Standards and Technology

NLETS - International Justice and Public Safety Network

NIMS - National Incident Management System

NPSTC - National Public Safety Telecommunications

OASIS - Organization for the Advancement of Structured Information Standards

OASIS EMTC - OASIS Emergency Management Technical Committee

ODNI - Office of the Director of National Intelligence

OGC - Open Geospatial Consortium

OJP - Office of Justice Programs

PIDF - Presence Information Data Format

PKI - Public Key Infrastructure

PSAP - Public Safety Answering Point (associated with ECC)

PSTN - Public Switched Telephone Network

SAFECOM - Communications Program of DHS's Office for Interoperability and Compatibility

SAP - Standard Access Point

SI - Services Interface (in the context of BISACS)

SIA - Security Industry Association

SIP - Session Initiation Protocol

SOAP - Simple Object Access Protocol

TCP - Transmission Control Protocol

TDM GW - Time Division Multiplexing Gateway

TIA - Telecommunications Industry Association

TLS - Transport Layer Security

TTY - Hearing Impaired Communication Device

UL - Underwriters Laboratories

URI - Uniform Resource Identifier

URL - Uniform Resource Locator

VoIP - Voice over Internet Protocol

VPN - Virtual Private Network

Web - System of interlinked hypertext documents contained on the internet

$\mathrm{XML}$ - eXtensible Markup Language 


\section{Appendix B. Smart Fire Panel project paper by section}

\subsection{Vision}

“Interoperable Dynamic Tactical Information for Public Safety,” W. D. Davis, D. D. Evans $[4]$

\subsection{Review of Important Publication on Smart Fire Panels}

"Using Sensor Data to Predict the Environment in a Building," W. W. Jones, R. D. Peacock, G. P. Forney, P. A. Reneke[5]

"Using High Reliability Detection for Fire Service Response in Building," W. W. Jones, R. W. Bukowski [6]

"Critical Information for First Responders, Whenever and Wherever It Is Needed," W. W. Jones, R. W. Bukowski [7]

"Building Tactical Information Systems for Public Safety Officials, Intelligent Building Response (iBR),” D. G. Holmberg, William D. Davis, Stephen J. Treado, Kent A. Reed [8]

“Smart Talk," D. G. Holmberg [9]

“Intelligent Building Respons,” W. D. Davis [10]

\subsection{Data}

“Interoperable Dynamic Tactical Information for Public Safety,” W. D. Davis, D. D. Evans [4]

"Workshop to Define Information Needed by Emergency Responders During Building Emergencies,” W. W. Jones, D. G. Holmberg, W. D. Davis, S. T. Bushby, K. A. Reed [20]

\subsection{Networks}

“Building Information for Emergency Responders," S. J. Treado, A. Vinh, D. G. Holmberg, Micheal Galler [21]

"Building Information Services and Control System (BISACS): Technical Documentation, Revision 1.0," A. Vinh [22]

"Computer-based Monitoring for Decision Support Systems and Disaster Preparedness in Buildings," A. Vinh [23, 24] 
"Building Information Exchange for First Repsonders Workshop: Proceeding October 1516, 2008," J. D. Averill, D. G. Holmberg, W. D. Davis [25]

“Connection Buildings to Public Safety Networks,” A. Vinh, D. G. Holmberg [26, 27]

\subsection{Evaluation Conditions}

"New Approaches to the Interpretation of Signals from Fire Sensors," R. W. Bukowski, P. A. Reneke [30, 31, 32]

“A Sensor-Driven Fire Model,” W. D. Davis, G. P. Forney [35, 36]

“A Sensor-Driven Fire Model, Version 1.2,” W. D. Davis [43]

"Using Sensor Signals to Analyze Fires," W. D. Davis, T. G. Cleary, M. K. Donnelly, S. Hellerman [44]

"Discriminating Between Smoldering and Flaming Fires Using Alarm Signals," W. D. Davis [45]

“Alarm Information for Decision Support,” W. D. Davis, S. Kerber, A. Barowy [46]

"Modeling Smoldering Fires Using the Computer Model CONTAM,"W. D. Davis [47]

"Studying the Response of Building Systems to Fire Using a Virtual Cybernetic Building Test-Bed" W. D. Davis [49]

\subsection{Presenting Information to First Responders}

"Workshop on the Evaluation of a Tactical Decision Aid Display," W. D. Davis, R. L. Vettori, P. A. Reneke, L. D. Brassell, D. G. Holmberg, J. Kostecki, J. Kratchman [51]

"Demonstration of Real-Time Tactical Decision Aid Displays," W. D. Davis, D. G. Holmberg, P. A. Reneke, L. D. Brassell, R. L. Vettori [52] 


\section{References}

${ }^{1}$ Nelson, H. E., "Functional Programming/Research Planning for high Technology Federal Office Buildings.” Nat. Inst. Stand. Technol. NISTIR 84-2828:28 (1984)

${ }^{2}$ Karter, M. J., "Fire Losses in the United States during 2006" National Fire Protection Association (2007)

${ }^{3}$ TriData Corp, "The Economic Consequences of Firefighter Injuries and There Prevention." Final Report. NIST GCR 05-874.

${ }^{4}$ Davis, W. E., Evans, D. D., "Interoperable Dynamic Tactical Information for Public Safety Officals", Fire Suppression and Detection Research Application, $8^{\text {th }}$ Annual Symposium. Society for Fire Proection Engineers. Proceedings. Jan 12-23, 2004, Orlando, FL. 1-9 pp (2004) 5 Jones, W. W., Peacock, R. D., Forney, G. P., Reneke, P. A., "Using Sensor Data to Predict the Environment in a Building" Fire Suppression and Detection Research Application Symposium. Research and Practice: Bridging the Gap. Proceedings. National Fire Protection Research Foundation. Feb. 25-27, 1998, Orlando FL, 60-63 pp (1998)

${ }^{6}$ Jones, W. W., Bukowski, R. W., "Using High Reliability Detection for Fire Service Response in Buildings" International Conference on Automatic Fire Detection (AUBE01), $12^{\text {th }}$.

Proceedings. Nat. Inst. Stand. Technol. March 25-28, 2001 Gaithersburg MD Beall, K, Grosshandler, W. L., Luck, H. Editors, 574-579 pp, (2001)

${ }^{7}$ Jones, W. W., Bukowski, R. W., "Critical Information for First Responders, Whenever and Wherever It Is Needed” Interflam 2001 (Interflam01) International Interflam Conference $9^{\text {th }}$ Proceedings. Vol. 2, Sept 17-19, 2001, Edinburgh, Scotland, Interscience Communications Ltd., London England, 1073-1082 pp (2001)

${ }^{8}$ Holmberg, D. G., Davis, W. D., Treado, S. J., Reed, K. A., Nat. Inst. Stand. Technol. NISTIR 7314, Gaithersburg MD (2006)

${ }^{9}$ Holmberg, D. G., "Smart Talk" Fire Chief, Vol. 50, No 8, 54-58, Aug (2006)

${ }^{10}$ Davis, W. D., "Intelligent Building Response" Fire Protection Engineering, No. 33; 26, 30, 32, 34, 36, Winter (2007)

${ }^{11}$ Busby, S. T., “A New Age in Building Control Systems”, Construction Business Review, 6065, Mar/Apr (1994)

12 ANSI/ASHRAE Standard 135-2010: "BACnet - A Data Communication Protocol for Building Automation and Control Networks", American Society of Heating Refrigerating and Air-Conditioning, Atlanta, GA.

${ }^{13}$ EN ISO 16484-5, "Building automation and control systems - Part 5: Data communication protocol."

${ }^{14}$ Bushby, S.T. "BACnet ${ }^{\mathrm{TM}}$ - A Standard Communication Infrastructure for Intelligent Buildings", Automation in Construction, Vol. 6 No. 5-6, 1997, p. 529-540.

${ }^{15}$ Bushby, S.T. "Integrating Fire Systems With Other Building Automation and Control Systems", NISITR 6588, November, 200. U.S./Japan government Cooperative Program on Natural Resources (UJNR). Fire Research and Safety. Joint Panel Meeting. Volume 2. Proceedings. March 1-7, 2000, San Antonio, TX, Bryner, S.L., Editor, 349-356 pp, 2000.

${ }^{16}$ Bushby, S.T. "Integrating Fire Alarm Systems with Building Automation and Control Systems", Fire Protection Engineering, Issue 11, Summer 2001, p. 5-11. 
${ }^{17}$ Fenves, S. J., Wright, R. N., Stahl, F. I., Reed, K., A., "Introduction to SASE: Standards Analysis, Systhesis and Expression," Technical Note 940, NBS, Washington DC, 1987.

${ }^{18}$ International Organization for Standardization (ISO), "ISO 10303: Industiral Automation Systems and Integration - Product Data Representation and Exchange," ISO Cenral Secretariat, Geneva, Switzerland, 1995

${ }^{19}$ Fenves, S. J., Garret, J. H., Jr., Killiccote, H., Law, K. H., Reed, K. A., "Computer Representations of Design Standards and Building Codes: U. S. Persepective," International Journal of Construction Information Technology, Vol 3, No 1, 13-34, Summer 1995

${ }^{20}$ Jones, W. W., Homlberg, D. G., Davis, W. D., Bushby, S. T., Reed, K. A., "Workshop to Define Information Needed by Emergency Responders During Building Emergencies" Nat. Inst. Stand. Technol. NISTIR 7193, Jan (2005)

${ }^{21}$ Treado, S. J., Vinh, A., Holmberg, D. G., Galler, M., "Building Information for Emergency Responders", Systemics, Cybernetics and Informatics, $11^{\text {th }}$ World Multi-conference (WMSCI 2007). Proceedings. Vol. 3. Jointly with the Information Systems Analysis and Synthesis: ISAS 2007, $13^{\text {th }}$ International conference. July 8-11, 2007, Orlando FL, Callaos, N., Lesso, W., Zinn, C. D., Yang, H., Editors, 1-6 pp, (2007)

${ }^{22}$ Vinh, A., "Building Information Services and Control System (BISACS): Technical Docmentation, Revision 1.0" Nat. Inst. Stand. Technol. NISTIR 7466 Gaithersburg, MD (2007)

${ }^{23}$ Vinh, A., "Computer-based Monitoring for Decision Support Systems and Disaster Preparedness in Buildings," International Multi-Conference on Engineering and Technology Innovation (2008 IMETI), Vol. II, June 29-July 2, 2008, Orlando, FL (2008) ${ }^{24}$ Vinh, A., "Computer-based Monitoring for Decision Support Systems and Disaster Preparedness in Buildings", J. Systemics, Cybernetics and Informatics, Vol. 7 No. 2 51-56. (2009)

${ }^{25}$ Averill, J. D., Holmberg, D., Vinh, A., Davis, W., "Building Information Exchange for First Responders Workshop: Proceedings October 15-16, 2008.” Nat. Inst. Stand. Technol. Tech Note 1643, 60 Pages (December 2011).

${ }^{26}$ Vinh, A. and Holmberg, D. C., "Connection Buildings to Public Safety Networks", International Multi-Conference on Engineering and Technology Innovation (IMETI 2009).

Proceedings. Vol. 3. July 10-13, 2009, Orlando FL 199-203 pp, (2009)

${ }^{27}$ Vinh, A. and Holmberg, D. C., "Connecting Buildings to Public Safety Networks" $7^{\text {th }}$ International Conference on Computing, Communications and Control Technologies (CCCT 2009), July 10-13 2009, Orlando FL (2009)

${ }^{28}$ Peacock, R. D., Jones, W. W., Reneke, P. A., Forney, G. P., "CFAST - Consolidated Model of Fire Growth and Smoke Transport (Version 6): User's Guide." Nat. Inst. Stand. Technol. Spec. Pub. 1041, Gaithersburg MD, 97 p. Dec. 2008

${ }^{29}$ McGrattan, K., McDermott, R., Hostikka, S., Floyd, J., "Fire Dynamics Simulator (Version 5) User's Guide.” Nat. Inst. Stand. Technol. Spec. Publ. 1019-5, Gaithersburg MD, 222 p. October 2007

${ }^{30}$ Bukowski, R. W., Reneke, P. A., "New Approaches to the Interpretation of Signals From Fire Sensors" Fire Suppression and Detection Research Application Symposium. Research and Practice: Bridging the Gap. Proceedings. Fire Protection Research Foundations. Feb 24-27, 1999, Orlando, FL, 55-64 pp (1999) 
${ }^{31}$ Bukowski, R. W., Reneke, P. A., "New Approaches to the Interpretation of Signals from Fire Sensors" International conference on Automatic Fire Detection (AUBE 99), $11^{\text {th }}$ Proceedings. University of Duisburg. Mar 16-18, 1999 Duisburg, Germany, Luck H. Editor, 11-21 pp, (1999)

${ }^{32}$ Bukowski, R. W., Reneke, P. A., "New Approaches to the Interpretation of Signals from Fire Sensors" Sensors Expo Proceedings. Sponsored by Sensors Magazine. May 4-6, 1999, Baltimroe MD, Helmers Publishing, Inc., Peterborough, NH, 2910298 pp (1999)

${ }^{33}$ Ramsay, J. O., Silverman, B. W., "Functional Data Analysis." Springer-Verlag New York 1997.

${ }^{34}$ Peacock, R. D., Reneke, P. A., Davis, W., Jones, W. W., "Quantifying Fire Model Evaluation Using Functional Analysis." Fire Safety Journal, Vol. 33, 167-184, 1999.

${ }^{35}$ Davis, W. D., Forney, G. P., “A Sensor-Driven Fire Model, Version 1.1” Nat. Inst. Stand. Technol. NISTIR 6705 (2001)

${ }^{36}$ Davis, W. D., Forney, G. P., "Sensor-Driven Fire Model” International Conference on Automatic Fire Detection (AUBE01), $12^{\text {th }}$ Proceedings. Nat. Inst. Stand. Technol. March 25-28 2001, Gaitnersburg MD, Beall, K., Grosshandler, W. L., Luck, H., Editors 495-505 (2001) ${ }^{37}$ Davis, W. D., Notarianni, K. A., "Prediction Based Design of Fire Detection for Buildings with Ceiling Heights Between 9 m and 18 m." Nat. Inst. Stand. Technol. NISTIR 6199, Gaithersburg MD, 47 p July 1998.

${ }^{38}$ Davis, W. D., "Zone Fire Model Jet: A Model for the Prediction of Detector Activation and Gas Temperature in the Presence of a Smoke Layer.” Nat. Inst. Stand. Technol. NISTIR 6324, Gaithersburg MD, 55 p, May 1999.

${ }^{39}$ Davis, W. D., Notarianni, K. A., Tapper, P. Z. "Algorithm for Estimating the Plume Centerline Temperature and Ceiling Jet Temperature in the Presence of a Hot Upper Layer." Nat. Inst. Stand. Technol. NISTIR 6178, Gaithersburg MD, 27p June 1998.

${ }^{40}$ Davis, W. D., Notarianni, K. A., McGrattan, K. B., "Comparison of Fire Model Predictions with Experiments Conducted in Hanger with a 15 m Ceiling." Nat. Inst. Stand. Technol. NISTIR 5927, Gaithersburg MD, 61 p Dec. 1996

${ }^{41}$ Gott, J. E., Lowe, D. L., Notarianni, K. A., Davis, W. D., “Analysis of High Bay Hangar Facilities for Fire and Detector Sensitivity and Placement." Nat. Inst. Stand. Technol. NIST TN 1423, Gaithersburg MD, 325 p, Feb. 1997.

${ }^{42}$ Davis, W. D., "The Zone Fire Model Jet 2.0: A Model that Predicts the Activation of Heat, Smoke and Gas Alarms in the Ceiling Jet in the Presence of a Smoke Layer." Nat. Inst. Stand. Technol. NIST SP 1114, Gaithersburg MD, 71 p Jul. 2010.

${ }^{43}$ Davis, W. D., "A Sensor-Driven Fire Model, Version 1.2.” Nat. Inst. Stand. Technol. NIST SP 1110, Gaithersburg MD, 41 p, Jul. 2010

${ }^{44}$ Davis, W. D., Cleary, T. G., Donnelly, M. K., Hellerman, S., "Using Sensor Signals to Analyze Fires" Research and Practice: Bridging the Gap. Fire Suppression and Detection Research Application Symposium, Proceedings. Fire Protection Research Foundation, Tampa FL Jan 23-25, 2002, 205-224 p, (2002)

${ }^{45}$ Davis, W. D., "Discriminating Between Smoldering and Flaming Fires Using Alarm Signals", Nat. Inst. Stand. Technol. NISTTN 1684, Gaithersburg MD (2010)

${ }^{46}$ Davis, W. D., Kerber, S. Barowy, A., “Alarm Information for Decision Support”, Nat. Inst. Stand. Technol. NISTTN 1614, Gaithersburg MD (2010)

${ }^{47}$ Davis, W. D., "Modeling Smoldering Fires Using the Computer Model CONTAM." Nat. Inst. Stand. Technol. NIST TN 1685, Gaithersburg MD, 43 p Dec. 2010. 
${ }^{48}$ Walton, G. N., Dols, W. S., "CONTAM 2.1 Supplemental User Guide and Program Documentation.” Nat. Inst. Stand. Technol. NIST IR 7049, Gaithersburg MD, 101 p, 2003.

${ }^{49}$ Davis, W. D., "Studying the Response of Building Systems to Fire Using a Virtual Cybernetic Building Test-Bed" Fire Suppression and Detection Research Application Symposium. Proceedings. Fire Proection Research Foundation. Jan 22-24, 2003, Orlando FL, 412-421 pp, (2003)

${ }^{50}$ Park, C., Reneke, P. A., Galler, M. A., Bushby, S. T., Davis, W. D., "Enhancement of the Virtual Cybernetic Building Testbed to Include a Zone Fire Model with HVAC Components", Nat. Inst. Stand. Technol. NISTIR 7414 Gaithersburg MD (2007)

${ }^{51}$ Davis, W.D. Vettori, R. L., Reneke, P. A., Brassell, L. D., Holmberg, D. G., Kostecki, J., Kratchman, J. "Workshop on the Evaluation of a Tactical Decision Aid Display", Nat. Inst. Stand. Technol. NISTIR 7268 Oct. (2005)

${ }^{52}$ Davis, W. D., Holmberg, D. G., Reneke, P. A., Brassell, L. D., Vettori, R. L., "Demonstration of Real-Time Tactical Decision Aid Displays", Nat. Inst. Stand Technol. NISTIR 7437, Gaithersburg MD (2007) 